\section{COVID-19 driven challenges in international B2B customer relationship management: empirical insights from Finnish high-tech industrial microenterprises}

Customer relationship management

\author{
Ahmad Arslan
}

Department of Marketing, Management and International Business, University of Oulu, Oulu, Finland

Ismail Golgeci

Department of Business Development and Technology, Aarhus University, Herning, Denmark

Zaheer Khan

Business School, University of Aberdeen, Aberdeen, UK

Petri Ahokangas

Martti Ahtisaari Institute, University of Oulu, Oulu, Finland, and

Lauri Haapanen

Department of Marketing, Management and International Business, University of Oulu, Oulu, Finland

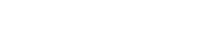

\begin{abstract}
Purpose - This paper aims to focus on the influences of the COVID-19 pandemic on business-to-business (B2B) firms' relationship initiation and customer relationship management in an under-explored and unique context of high-tech industrial microenterprises. The authors analyze the challenges posed by the COVID-19 pandemic in the specific context of $\mathrm{B} 2 \mathrm{~B}$ relationship initiation and customer relationship management dynamics by examining Finnish B2B industrial microenterprises.

Design/methodology/approach - The paper uses exploratory in-depth case studies undertaken in three Finnish industrial microenterprises to analyze the influences of the COVID-19 pandemic on their new business relationship initiation and relationship management with the current customers.

Findings - The case firms quickly adjusted to the "new normal" and used a number of technological resources, including online meetings and three-dimensional demonstrations, among others. A key reason for
\end{abstract}

(C) Ahmad Arslan, Ismail Golgeci, Zaheer Khan, Petri Ahokangas and Lauri Haapanen. Published by Emerald Publishing Limited. This article is published under the Creative Commons Attribution (CC BY 4.0) licence. Anyone may reproduce, distribute, translate and create derivative works of this article (for both commercial and non-commercial purposes), subject to full attribution to the original publication and authors. The full terms of this licence may be seen at http://creativecommons.org/ licences/by/4.0/legalcode 
IJOA 30,7

this quick adjustment was them being microenterprises. However, despite this, lack of access to customer sites remained a hindrance as their products need to fit certain production processes, which cannot be done without physical visits. Furthermore, the development of trust with new customers, especially those based in emerging markets, was challenging due to the lack of physical meetings and site visits.

Research limitations/implications - The research highlights the challenges posed by the COVID19 pandemic to B2B relationships and gives an account of the changing dynamics of relationship initiation and customer relationship management amid technological and societal disruptions. It also highlights the continued role of personal relationships and psychical meetings in such relationships. As such, the research informs B2B research that examines the role of personal relationships in $\mathrm{B} 2 \mathrm{~B}$ marketing.

Practical implications - The study offers industrial microenterprise executives insights into how to face and tackle COVID-19 driven challenges in B2B customer relationship management and how to integrate technological tools in relationship management practices while understanding where face-to-face meetings are indispensable.

Originality/value - The study demonstrates areas in which virtual tools can and cannot be substitutes for conventional means of $\mathrm{B} 2 \mathrm{~B}$ relationship initiation and customer relationship management across developed and emerging markets. It also highlights the specificities of industrial microenterprises and their business development and customer relationship management dynamics mechanisms, a research area that has been rather ignored by prior studies.

Keywords Business-to-business marketing, Microenterprises, COVID-19, B2B relationships, COVID-19, Customer relationship management, Microenterprises, Trust

Paper type Research paper

\section{Introduction}

Business-to-business (B2B) relational dynamics has received significant research interest from industrial marketing and management scholars. Extant studies indicate the importance of personal relationships in $\mathrm{B} 2 \mathrm{~B}$ relationship initiation and customer relationship management in the B2B context. Scholarships suggest that B2B relationships benefit from more personal (human touch) relationships as they tend to result in enhanced knowledge development and sharing between the exchange partners (Kotabe et al., 2003), a better understanding of complex inter-organizational issues (Kogut and Zander, 1992) and greater trust (Doney and Cannon, 1997; Calhoun and Harnowo, 2015), which result in reduced conflict and increased synergy between the exchange parties (Mohr and Spekman, 1994; Barmeyer et al., 2020). In such settings, employees acting as boundary-spanners between various business exchange firms play a vital role in creating value for the firms involved in complex B2B activities. Thus, personal relationships between boundary-spanning agents of B2B partners are arguably the cornerstone of the management of business activities and long-lasting trust-worthy relationships across organizational boundaries.

Furthermore, prior research has argued that one of the key drivers of personal relationship development is informal and personalized physical meetings between executives involved in business exchange (ALHussan et al., 2017). Many business contracts, especially in industrial settings, can have sophisticated attributes and a high value attached to them. In this context, personal meetings and connections are argued to be very important for initiating new B2B relationships in the industrial context due to technical and social issues involved in such settings (Davies and Hobday, 2005; Lehtimäki et al., 2009). First, in many industrial contexts, physical visits are needed to determine the appropriateness of the machinery or industrial equipment being sold (installed) as well as technical adjustments needed on both sides for it to work well (Davies and Hobday, 2005; Takala et al., 2007). Second, in many cases, the orders can be of large value. Hence, the development of trust and personalized understanding through physical meetings are important between the exchange parties (Walker and Rowlinson, 2007). 
This is why many executives and technical personnel (including engineers) of industrial firms spend much time traveling to their customers' locations, which can be spread across the globe.

However, despite significant prior research examining B2B relationships and the importance of personal relationships in such relationships, little research has investigated the role of personal relationships formed between the boundary-spanning employees of partner firms (Gligor and Autry, 2012) and how these are affected through external crises such as the recent COVID-19 pandemic. While communication has been a significant theme in B2B marketing research (Murphy and Sashi, 2018), less attention has been paid to the role of different forms of communication (e.g. face-to-face vs virtual) in B2B relationships.

Furthermore, the COVID-19 pandemic has created major disruption to many businesses (Arslan et al., 2021a), including B2B industrial firms (Cortez and Johnston, 2020; Crick and Crick, 2020), which have yet to be explored in a scholarly fashion. Due to the cancellation of flights, physical distance regulations, working from home and other restrictions (Arslan et al., 2021b), visits to the current and potential new customers' sites became nearly impossible. Even though virtual meetings and the use of other advanced technologies like three-dimensional (3D) demonstrations have offset some of the negative influences of these restrictions, many business elements associated with such firms cannot be undertaken remotely. This overlooked aspect of the COVID-19 pandemic vis-à-vis B2B relationships forms the starting point of our paper. As such, we aim to analyze the challenges posed by the COVID-19 pandemic in a specific context of B2B relationship initiation and customer relationship management dynamics by examining Finnish B2B industrial micro-enterprises (less than 10 employees). The focus on industrial microenterprises is unique as most prior studies have tended to bundle microenterprises in the small and medium-sized enterprises category, which results in ignoring specificities of microenterprises (Arslan et al., 2020). It is also rare for academic studies to analyze industrial microenterprises engaging in the hightech industrial manufacturing process, which is mostly viewed as the key domain of large or medium-sized enterprises. Hence, our paper is positioned to contribute to both general microenterprises research literature as well as research on B2B relationships management, especially during disruptive events like the COVID-19 pandemic.

Our study contributes to the extant microenterprise and B2B relationship literature in three important ways. First, the paper is a pioneering study focusing on the specificities associated with physical meetings with the current and future customers of the industrial microenterprises in the context of the COVID-19 pandemic. Second, our study specifically addresses the cognitive dynamics associated with a lack of physical meetings in the case firms concerning B2B relationship initiation as well as existing customer relationship management and how in certain situations, modern technologies can compensate to an extent, the need for face to face interactions. Finally, it offers practical insights into the usefulness of telecommuting and other technologies like 3D demonstrations in such circumstances and highlights their limitations in dealing with external crises and the formation of trust between exchange partners across developed and emerging markets.

\section{Literature review}

\subsection{International business-to-business customer relationship management and the role of personal relationships in business-to-business relationships}

Customer relationship management is defined as "the building and managing of customer relationships on an organizational level through understanding, anticipating and managing of customer needs, based on knowledge gained of the customer, to increase organizational effectiveness and efficiency and thereby increasing profitability" (Plessis and Boon, 2004, p. 77). It represents a set of relational practices that firms adopt to enhance customer relationships

\section{Customer relationship management}

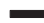


IJOA

30,7

(Padmavathy et al., 2012). As its definition indicates, customer relationship management sits at the epicenter of B2B marketing. As long-term and involved relationships are more prevalent in B2B settings and form the basis of exchange in B2B marketing (Håkansson and Snehota, 1989), international B2B customer relationship management also emerges as an important element of international B2B marketing. Firms undertaking their B2B marketing strategies in international contexts are also compelled to adopt international B2B customer relationship management practices to achieve their goals and keep their foreign partners (e.g. customers and suppliers) satisfied (Luo et al., 2004).

Personal relationships constitute the primary underlying domain of international B2B customer relationship management. They are built and executed by individual boundaryspanners, whom we refer to as organizational members who link their organization with the external environment (Williams, 2002). Extant research has revealed that the management of collaborative B2B relationships underpinned by boundary-spanners leads to enhanced knowledge development and sharing as well as the development of trust and reduced conflict (Kotabe et al., 2003; Mohr and Spekman, 1994). The boundary spanners are invaluable conduits to inter-organizational communication that is an essential element of B2B relationships (Murphy and Sashi, 2018). They underlie B2B relationships in a fundamental way and are the backbone of effective inter-organizational relationship governance. Such personal relationships between boundary-spanning agents of B2B partners are a cornerstone of the management of business activities across organizational boundaries.

However, despite the importance of personal relationships in $\mathrm{B} 2 \mathrm{~B}$ relationships and the wealth of research examining B2B relationships, little research has investigated the role of personal relationships formed between partner firms' boundary-spanning employees (Gligor and Autry, 2012); even more so in the case of microenterprises. The formation and management of personal relationships are manifested differently from purely business relationships, and therefore, personal relationships exhibit different characteristics from purely business relationships. Some of these differences are as follows. First, while personal relationships are usually emotion-based and intrinsic, business relationships are instrumental with reciprocal expectations (Jeong, 2016; Varoutsa and Scapens, 2018). Second, while personal relationships tend to be relatively more informal, business relationships are more formal in their manifestation (Price and Arnould, 1999). Third, personal relationships enable the development of intimate social connections with greater potential of sharing tacit knowledge and opening up one to another. However, purely business relationships devoid of personal underpinnings may never reach the intimacy and closeness of personal relationships between firms' boundaryspanners (Fischer, 1982).

While personal relationships are different from business relationships, personal relationships are often an integral part of and play a fundamental role in B2B relationships. As most B2B relationships today are no longer arms-length with the transactional approach but entail a complex set of activities, deep and sophisticated involvement between parties and an intricate web of connections (Chandler et al., 2019; Hurley et al., 2005), the role played by personal relationships is amplified. The importance of personal relationships for microenterprises is even higher as intangible assets like these can potentially help them overcome resource limitations that hinder their competitive activities compared to large or medium-sized firms (Baluku et al., 2018)

In this context, it is important to mention that trust, as a fundamental facilitator of B2B relationships, requires time, effort and personal touch to develop (Doney and Cannon, 1997; Schilke and Cook, 2013). Personal relationships are fundamental to the development of trust (Baluku et al., 2018), which is constructed by individuals and deeply subjective and may not 
form in a mechanistic fashion. Moreover, personal relationships function as a catalyst of $\mathrm{B} 2 \mathrm{~B}$ relationships through their role in building bonds between the partners and enhancing B2B relationship strength (Baluku et al., 2018), as well as hedging against opportunism and relationship vulnerabilities (Crosby et al., 1990). These factors help in decision-making on strategic issues between the parties, as such decisions are often made through physical and personal interactions and sophisticated negotiation processes. Furthermore, once the first contact is established between the exchange partners, the partners gradually develop norms of and expectations from B2B relationships, where physical meetings are mostly indispensable (Davies and Hobday, 2005; Walker and Rowlinson, 2007). Physical connections and personal relationships are essential to lay out tangible details, share important knowledge, including technical (installation) specificities for industrial firms and account for behavioral patterns between the partners.

While digital tools and digital marketing practices have profoundly shaped the way B2B relationships are managed (Hofacker et al., 2020), the human element tends to persist and manifest its role in evolving ways. Thus, the COVID-19 pandemic poses several challenges to B2B microenterprises and how boundary-spanners develop cognitive ties with their exchange partners. Such cognitive ties are vital for the formation of trust between the exchange partners to overcome external shocks.

\subsection{Business to business relationships in times of crisis such as the COVID-19}

Many B2B relationships are subject to both internally and externally-driven ups and downs during their life span (Autry and Golicic, 2010; Nätti et al., 2014). Past research shows that environmental uncertainty and adverse environmental conditions have fundamental influences on work relationships within and across firms' boundaries (Matanda and Freeman, 2009; Williams et al., 2017). The COVID-19 pandemic has demonstrated that many businesses turn upside down when a crisis hits. Likewise, the way they manage relationships with their partners may drastically change during "force majeure" situations (Gölgeci et al., 2018). As such, times of crisis are when relationships are often tested and relationship development and management practices are subject to drastic changes.

One such change in $\mathrm{B} 2 \mathrm{~B}$ relationship development and management practices can be about how business partners and their boundary-spanning employees interact and communicate. For example, the COVID-19 driven lockdown in many countries forced marketers to break out of established patterns of thinking and marketing practices (Cankurtaran and Beverland, 2020). Many meetings and communication activities had to be moved online. In fact, virtual communication and digital marketing practices have been a growing trend in B2B relationships even before the COVID-19 crisis (Hofacker et al., 2020; Mullins and Panagopoulos, 2019). The COVID-19 crisis has rapidly accelerated an already visible trend across organizations.

On the other hand, despite the growing prevalence of virtual communication and digital marketing practices in $\mathrm{B} 2 \mathrm{~B}$ relationships and drastic changes caused by the COVID-19 crisis (Crick and Crick, 2020), relatively little is known about the psychological or cognitive challenges that B2B partners' boundary-spanners face when managing their business relationships and what practices are more likely to be more permanent versus what practices are likely to be temporary in the aftermath of the crises. In particular, whether and how virtual communication and interaction between boundary-spanners in the face of the COVID-19 crisis can replace physical meetings and place-bounded personal relationships remain to be seen. Likewise, drastic changes in boundary-spanners' working patterns during the crisis period (Hartmann and Lussier, 2020) may have unexplored repercussions in the way they do their work and interact with their business partners. Accordingly, we scrutinize B2B

\section{Customer relationship management}


IJOA 30,7

relationship initiation and relationship management practices of Finnish industrial microenterprises in the backdrop of the COVID-19 crisis and adopt an exploratory approach.

\section{Research design and methodology}

The COVID-19 has been a highly unexpected phenomenon and far as we know, our research is one of the first attempts to understand how B2B firms' virtual communication and digital marketing practices adapt to such a global shock. In general, the adoption of qualitative methodology is justified in situations where research is strongly leaning on empirical evidence to gain a holistic view of the phenomenon and develop new theoretical insight (Eisenhardt, 1989). To gain a rich and in-depth insight, we use an exploratory qualitative case study approach (Patton, 2002; Yin, 2009) and examine three Finnish microenterprises, which were forced to discard their traditional marketing means.

We collected data from three Finnish high-technology microenterprises selling their products and services to paper, bulk and steel industries. We purposely selected the case firms to those enterprises that were urged to change their sales processes radically to stay in business during the current crisis. The dramatic change in the way these high-technology microenterprises conducted B2B relationships formed the basis of our sampling strategy and interview protocol. These enterprises were identified through personal research links and through snowballing strategies. As such, our interview protocol included open-ended questions on the kind of industrial customers, B2B communications and interactions between boundary-spanners pre and during COVID-19 pandemic, the impact of the COVID19 pandemic on microenterprises' business and marketing practices, working patterns of boundary-spanners and psychological or cognitive challenges that boundary-spanners face in association with the COVID-19 pandemic across developed and emerging markets.

We collected our primary data by using semi-structured in-depth face-to-face interviews during May and June 2020. We interviewed the case firms' chief executive officers (CEOs) as they are both key decision-makers and the most critical boundary-spanners of their microenterprises responsible for dealing with their key clients. They have had a key role both in prior COVID-19 sales negotiations and in modifying firm practices to adapt to the new situation given the size of their firms (microenterprises). During the interviews, we focused on key themes outlined in the interview protocol, but we kept the interviews' guide flexible to get rich data. We let the informants speak freely to see if any new aspects were about to rise through this approach. We also used other sources of secondary data, including case firms' annual reports and web pages. Resulted triangulated primary data (Eisenhardt, 1989; Creswell and Miller, 2000) provide a holistic insight into the phenomenon.

Data saturation is an important matter when conducting qualitative research. Thus, evaluating how many interviews are adequate to fulfill the research goals is necessary. As data collection proceeds, observing similar patterns recurrently supports the confidence that no substantially different findings can be achieved with further interview data collection. In this vein, in the context of this research, the overall exploration of COVID-19 driven challenges in international B2B customer relationship management of Finnish high-tech firms does not require a large sample base to gain fundamental insights. As such, the current study sample was deemed sufficient to gain overall insights and reveal fundamental aspects of the COVID-19 driven challenges in international B2B customer relationship management endeavors.

All interviews were recorded and in the next phase, the recordings were transcribed. As our thematic interview guide allowed the informants to discuss freely, the order of the themes did not strictly follow the guidelines. During the interviews, informants were very open and discussions roamed and often deviated from the predefined themes. We followed a 
three-step open thematic content analysis in the data analysis (Corbin and Strauss, 2014). In the first phase, we reduced the data to reveal the main themes and constructs. Next, we collected our primary and secondary data under these themes. To identify the pertinent patterns in our data, we re-arranged the interviews according to interview themes and at the same time, we also referred to our secondary data. In doing this, we made a distinction between common and differing observations. Finally, in the last phase, we analyzed and arranged our findings and to develop a holistic picture, the final themes were then compared with the extant literature.

\section{Findings}

\subsection{Case descriptions}

The first case firm, Sapotech, is a Finnish high-technology firm designing machine visionbased solutions for their industrial customers. Customers are mainly large metal and steel manufacturing firms. In 2017, Sapotech started distribution cooperation with Vesuvius, a large MNE listed in the London stock exchange providing steel and foundry industries with engineering services globally. Vesuvius has a unit, which is responsible for the cooperation with Sapotech. Subsequently, Sapotech has been training more than a hundred Vesuvius salespersons to be able to sell Sapotech products. The CEO of Sapotech notes, "In my view, it is more important that they know that our products exist; this is more like a marketing channel." We present the case firm details in Table 1.

The second case firm, Luxmet, is a Finnish university spin-off company that uses optical emissions spectrometry to monitor and control steelmaking in electric arc furnaces (EAF). The company was founded in 2014 to commercialize the technology stemming from a series of research projects at the University of Oulu, Finland. The company has developed its solutions further in collaboration with domestic partners and has started three years to test the solutions with European partners. The typical sales cycle consists of a trial period with tailoring and calibration. After proving the benefits, the company either sells the solution as an investment or rents it out as a service. The company collaborates with local representatives or agents to open new customer relationships and install the solution. The company has been venture-capital-backed since December 2019.

The third case firm SFTec is also a university spin-off company founded in 2013 to commercialize a product idea stemming from the metallurgical industries' need for a more costefficient material dryer. SFTec manufactures and develops industrial dryers based on patented technology and also offers material drying as a service. The company provides innovative

\begin{tabular}{|c|c|c|c|c|}
\hline $\begin{array}{l}\text { Firm } \\
\text { characteristics }\end{array}$ & Sapotech & Luxmet & SFTec & \\
\hline Founded & 2012 & 2014 & 2013 & \\
\hline $\begin{array}{l}\text { Number of } \\
\text { employees }\end{array}$ & 8 & 6 & 7 & \\
\hline Turnover & $€ 1.5 \mathrm{~m}$ & $€ 0.2 \mathrm{~m}$ & $€ 0.5 \mathrm{~m}$ & \\
\hline Industry & $\begin{array}{l}\text { Machine vision-based } \\
\text { solutions for the } \\
\text { steelmaking industry }\end{array}$ & $\begin{array}{l}\text { Optical emissions } \\
\text { spectrometry-based control } \\
\text { solutions for the steelmaking } \\
\text { industry }\end{array}$ & $\begin{array}{l}\text { Industrial dryers for sidestream } \\
\text { materials to improve } \\
\text { metallurgical, pulp and paper } \\
\text { and organic material processes }\end{array}$ & \\
\hline $\begin{array}{l}\text { Locus of } \\
\text { operations }\end{array}$ & Global & Global & Europe & $\begin{array}{r}\text { Table } 1 . \\
\text { Description of case }\end{array}$ \\
\hline Interviewee & CEO & CEO & CEO & firms \\
\hline
\end{tabular}

\section{Customer relationship management}

55 
IJOA

30,7

technology and expertise in drying technologies, process engineering and circular economy. SFTec collaborates in its development and sales activities with its customers in a business cycle that starts with a small-scale demo to prove efficiency and continues with designing and building a large-scale dryer that improves and changes the customer's industrial process to make it more efficient.

\subsection{Importance of physical meetings (site visits)}

The three case firms are relatively small and young and they have been rapidly growing due to their business exchange with large industrial firms. To execute such growth, our case firms have been compelled to approach as many new potential customers as possible. To close the sales deals, case firms' boundary-spanners have been personally meeting and interacting with their potential and existing customers. The customers of all three case firms are large industrial firms and due to the specific nature of products and services offered by the case firms, the need for physical meetings with customers (including visits to their sites and factories) is important to share tacit knowledge and develop long-term trustworthy relationships. For the case firm Sapotech, its customers consist of large metallurgical firms, mainly iron and steel factories. The CEO notes, "In an outsider's eyes they all look alike, the manufacture iron and steel, yet they all are different, it is different to sell, different to make deals [...] the way to sell is different. Our products can be mass-customized; customers' production environments are always a bit different." This difference in customers' production environment is linked to the need for physical visits to their sites.

The customers of Luxmet produce steel with EAF. Luxmet's solution is patented and unique, but installation requires some work at the plant level as "every country, customer, plant and EAF is a bit different - we need to tailor specifically the cabling and data collection although the core, industrial PC and the software, are standard" according to Luxmet CEO. He continues that the "deployment of the solution also requires some work at customer premises as we need to train the operator and sometimes integrate the solution with the control system of the EAF." SFTec's CEO considers the company markets "unlimited, although the idea started with metallurgical industries, agricultural processes, paper, pulp industries, biogas production [...] almost whatever that needs to be dried, we have dried." However, the company decided to focus on the sidestreams of metallurgical industries, pulp and paper production and organic materials production. For SFTec, each customer is unique, partly due to their production process but also due to cultural and industry-specific differences.

Regarding the B2B relationship initiation before the COVID-19 pandemic, the CEO of Sapotech describes, "Quite often all contacts come from trade fairs [... .]. Thereafter we consider the commercial potential and technological feasibility, if it seems good, we quickly send a budgetary offer to the customer or alternatively, what we used to do more, we sell a demo project - we take a suitcase full of our stuff, one or two of our men goes to the customer [...] week or two at the site, in the real environment, we show what we are capable of, we make a quick report, fly back, we do a final report to the customer, the customer says if they are interested in and thereafter, we make a proper offer." Regarding the presence at the customer's site, the CEO notes, "For this reason, we have to consider who goes, we all have to master communication and technical sales skills and be able to acknowledge cultural differences."

The Luxmet solution is meant to be used as a part of the production line but is also linked to development activities at the factory level. Hence, there is a need for "very close collaboration and face-to-face interaction with the customer," the Luxmet CEO says. "We also use videos and telcos to support interaction." These activities take place when the company is already having a business case with the customer. As time goes by and the solution matures, the plan is to "reduce 
the amount of continuous, direct interaction in sales and installations," according to Luxmet CEO. External partners or agents who know the end customer personally are needed to get access to the customer and sometimes also to initiate the customer relationship. Luxmet CEO reflects, however, that "not a single case has been realized without direct personal meetings with the customers." So far, the same has held true also when starting relationships with new agents or representatives.

B2B relationship initiation needs physical meetings and site visits in case SFTec because the customers want to show their materials' specific works. As an example, "we started last year with a few day's small scale testing, then spent five weeks onsite with larger-scale testing, then spent half a year negotiating and now finally last week sent in the final offer," says the CEO of SFTec. Keeping in view all these details, the COVID-19 pandemic resulted in difficulties for the case firms, which they tried to address in a rather agile manner, as much as they could.

\subsection{Relationship initiation and customer relationship dynamics in pre and during the COVID-19 times}

It was evident from the data that relationships based on trust with their industrial customers were very important for them to deliver value for all three case firms. For this relationship development and strengthening, physical visits and meetings play an important role in exchanging tacit knowledge and developing cognitive proximity between exchange partners' boundary spanners. However, the frequency of these physical visits varies. For example, SFTec finalized its first full-scale delivery last year. After the delivery, the company has had weekly calls with the customer to check the situation but very few physical visits. "After deployment, we have paid two visits to the site. Even though our system is easy to use, operators need to be trained. If they adjust the systems themselves, without having the knowledge, things tend to accumulate to a point where we need to go and fix the problems," the CEO of SFTec explains.

In December 2019, Sapotech made its largest deal - throughout the times - with a South Korean customer. The CEO notes, "Now it is held. The customer said yes, we had made a purchasing order, yet, the deal continues when it continues, we cannot pressure them in the current situation. Another one was from Japan, we were supposed to get this deal in April and also, they noted that everything is ok, technical, commercial, all is ok, but we buy April next year. These are examples. However, they are remarkable incidents in that sense that they would have yielded between $1.5 \mathrm{~m}$ and $2 \mathrm{~m}$ euros turnover."

The CEO of Sapotech recalls how the COVID-19 pandemic was influenced by saying, "First came the big shock, the large deal was gone. [...]. What was positive was that we knew that deals would be postponed, but our service business will continue and bring us the cash flow [...] monthly payments and we know that they [our customers] will continue manufacturing steel." He continues, "We have those remote connections to our systems, we need to travel very little, yet we had this one delivery which was in progress, in January [. . .]February, they let us know that visits were no longer allowed to their factory [...] deliveries in such installation phases needed to be postponed and moreover, postponements come also with a financial challenge."

Luxmet is in a similar situation. In Finland, the company could continue with the development and installation activities after COVID-19 as long there was access to the customers' factories. Abroad, "all sales and installations activities ended abruptly," Luxmet CEO observed. As an additional consequence, already arranged customer visits from abroad were also halted when the customers could not travel to Finland to see the solutions installed here. As Luxmet had planned on transitioning from a start-up to a scale-up, the COVID-19

\section{Customer relationship management}


IJOA

30,7

consequences were rather straightforward. "You cannot plan for this kind of a thing and at this point, when we still have so few references, customers quite often want to come to see the references," Luxmet CEO observes.

For SFTec, too, the COVID-19 slowed down business. "For the spring, we had a couple of cases that were rather advanced in terms of offers, planning details, scheduling of measurements and implementation and in one week, all were postponed. We had agreed on plotting. All were postponed. Now, during the past two weeks, that the restrictions have been removed, all the cases have been reactivated at the same time," The CEO of SFTec said. The simultaneous reopening of the cases has, however, resulted in capacity problems: "As our business is rather cyclical and business is mostly done when there is no snow, so half of the opportunity has been lost. And we cannot be everywhere at the same time as our single mobile test system."

\subsection{Virtual meetings and other technological tools' role in response to COVID-19 pandemic} Rise of virtual (online) meeting tools for customer relationship management was visible in all three case firms. For example, according to SFTec co-founder and CEO, "In the old times, it was one or two calls or Teams meetings and then we went to meet the customer physically. Now we take it up to budgetary offer over the Teams.” The CEO of Sapotech further notes, "Nowadays, quite often we have received data, drawings, pictures, 3D pictures - customers have adapted to this situation, they know that we would like to pay visits, yet it is not possible." At Luxmet, the CEO also sees Zoom and Teams and videos in general as handy tools for remote meetings. The CEO thinks that "to me, it feels the same whether I am giving an online presentation with PowerPoint slides or if I am in the same place with the customer. I can see the faces and hear the discussion on the other side." From these discussions, it is visible that the case firms tried to overcome the barrier of physical meetings and clients' site visits by using technology to the extent it was possible. However, the respondents found a lack of personalized touch still a barrier. A good example of this was the partnership discussions the firm has in Poland, where the potential customer directly told Luxmet CEO that "no remote connections with us, we can continue the discussion when you come for a visit." Similarly, a steel factory owner in Turkey told the same CEO directly that "listen, my friend, I will not buy anything until I see it. Seeing is believing, especially as we are talking about new technology." This finding is in line with some prior studies where it has been argued that despite technological tools and access, personalized trust (based on physical meetings) building is essential in the B2B context, especially in cross-cultural and emerging markets' contexts (Khan and Nicholson, 2014; Barmeyer et al., 2020).

In the case of SFTec, a similar situation emerged due to the COVID-19 situation. The CEO specifically highlighted that "Yes, we continued with them, we became pretty well familiarized with Teams when working with the cases, we have kept the contact up all the time and clarified the plans. However, it can only be done up to a certain point. Then we need a site visit." There is a remarkable difference in creating trust by using remote tools, according to the CEO of SFTec: "All we have is this 'how are you' discussion and some other situation update discussions and that are all we have with what we need to survive with. There is a clear difference compared to what it used to be." The COVID-19 has made access to foreign customers more difficult than before. According to SFTec CEO, "virtual and remote meetings do not seem to work." "Last year, we were three weeks in the UK at a site, but continuation discussion has faded away for the most part [.. . . Similarly, in Sweden, we have a case that has been postponed to autumn time." Moreover, the fact that the company is 
not in the critical path of the customers' processes but focuses on sidestreams that have been the problem for decades influences the company situation, too.

When discussing if virtual and augmented reality would provide new possibilities in doing business, the CEO of Sapotech notes, "Not really [...] however, regarding our products, in our marketing, sales and even in the maintenance [...] in a matter, in fact, we discussed these issues yesterday with Vesuvius, possibly we will come up with a solution, the one that we have considered already eight years back, a person at the factory with his helmet on and augmented reality would help him to do the needed maintenance. [...] nice to have from the marketing point of view [. . . but this was not because of the pandemic."

In SFTec, the CEO observed that "however, small the case is and even though we have the blueprints and all the explanations of the site, we have to pay a visit there." The company participates in a university project that research studies the use of virtual reality in depicting the SFTec solution functionality and contents for maintenance and operation purposes, but that remains at a planning stage. The benefits have, however, been recognized by the company. Especially, as the company solutions will become more mature and experienced, the benefits of virtual reality could be easier to reach. In that direction, the company uses "WhatsApp videos since everybody has it" for maintenance and ad-hoc advice or training purposes. WhatsApp videos are the most accessible low-entry tool that the company and the customers have in common. Generally, for proofing the pilot outcomes and benefits, the company uses videos. Still, customers want proof. "We are a new innovative company with own technology entering the markets, that is the reason," the CEO of SFTec observes. "They have been running the sites for decades and tried themselves different things that either have not worked or have been too expensive: they need to see."

\subsection{The lack of physical meetings and customers' trust}

From a cognitive perspective, lack of physical meetings was seen as a detriment to the formation and maintenance of (personal) trust with the customers in all case firms. The CEO of Sapotech stresses, "I can say that in this last order that we received, mutual trust was the most important single factor, the fact that they trust us. [...] we had met in person, face-toface $[. .$.$] this is an extremely good customer, personal chemistries were matching all the$ way from the top management to the technical level." When discussing if the telecommunication tools can be used to build similar trust as sitting at the same table with a customer, the CEO of Sapotech notes, "No, but they provide me with the means to get me to the same table. During this spring, we have had few competitive biddings without meeting customers, ones that we have never met, then we have had a few Skype meetings, which does not yield good outcomes. One must meet." He continues, "We had this one invitation for tenders [...] last week, they placed an order for a demo, we never met, we have done this over Skype. I cannot say what this mutual trust was based on. Maybe it was our openness." He agrees that the fact that no one is able to travel, that is, everyone is in the same position, including competitors and buyers, is making the use of telecommunication tools a new normal. Regarding building trust, he continues, "Our advantage is the highly visual solution, they are machine vision system and that we can demonstrate them using the cloud, we can give a password to the customer, go and take a look by yourself and when meeting the customer in Teams or in Skype, instead of showing slides, we can open our application and show real data [... ] and if allowed, we can show real-time data from a real customer":

I assume that you cannot close big deals without trust and trust creation requires a face-to-face meeting." Luxmet CEO continues that "preliminary fact and information sharing are, of course, ok remotely, but doing business is always taking place between people. Contact and trust go hand-inhand and remotely it is not the same. This seems to be especially true for new customer cases. 
IJOA

30,7

60
With existing customers, it is easier". As such, interviewees highlighted that building trust with new customers requires physical contact, while maintaining trust with the existing customers may be possible using online tools. Luxmet CEO continues that "as a Finn, I have felt that we have this advantage that we are considered trustworthy collaborators. We are testing this with the Russians. We are negotiating a deal, not a big one, but a deal anyway, we have met only online and it is interesting to see if we can close it.

The role of a partner in trust creation is crucial, especially in the international markets. The CEO of Luxmet states that "outside our extended home markets, we always have a partner to help in trust creation. For example, in Turkey, we have a partner who knows all steel factory managers and also factory owners - personally, as he has been working there for decades with them. He acts as a kind of guarantee toward the customer for us." "Even if you had the best product in the world, but fail to deliver the message or customer doubts what you are saying or you cannot clarify your message so that the customer would trust you, there will be no deal."

These quotes indicate that some markets, especially the emerging ones, would require boundary-spanners to establish face-to-face connections, leading to the development of longlasting business relationships based on social ties and trust (Bouguerra et al., 2019; Khan and Nicholson, 2014). In performing basic sales, the Teams, Zoom and PowerPoint can offer a working solution, but they do not seem to work in installations. Luxmet's CEO says that "after COVID, we have speeded up development to make our solution easier to install and use so that anybody could technically do the installation." The development work has included technical development, new parts and documentation and instruction manuals and online training. The company has also started to prepare webinars together with researchers and industry experts about EAF-based steelmaking and the benefits of the Luxmet solution.

Luxmet sells unique and new technology that is not well known among customers yet. Therefore, the company has tried to quantify the benefits of the solution for the customer. The COVID-19 situation has influenced the company in two different ways, first halted practical development and installation activities in customers' factories but also made them more cost averse and look for cost reductions. As a consequence, Luxmet CEO thinks that they might also have an advantage by offering customers the solution as a service. This, however, requires that customers trust in the value proposition that is made by Luxmet. "We can bring the customer substantial cost savings and improved production yield - and also help the customer to become more environmentally friendly [...] this is why I am not overly worried about COVID. Unless the whole economy collapses." In a similar vein, the CEO of Sapotech also mentions that "[...] And yes, we are daily in touch using Skype and Teams. We just had a meeting with a customer from India, we were using this Zoom [... ] also this customer would like to have a demo, but we cannot travel."

"What we have learned is that up to a point, things can be done remotely - and they should be done remotely, too. We can save time and money on both sides. What happens when using Teams is that trust-creation just takes place a bit later and becomes more straightforward to start," the CEO of SFTec observes. "In creating trust, personal calls and one-on-one virtual Teams meetings can be used to compensate for the trust creation that normally takes place in physical meetings." These discussions suggest that technological tools can help to overcome some of the barriers concerning customer relationship management, including some trust-building. However, for the practical reasons associated with industrial work settings as well as cultural dynamics linked to trust development, physical meetings are and will remain important for the foreseeable future.

The following Table 2 summarized the study findings showing the similarities and differences in the case firms. 


\begin{tabular}{|c|c|}
\hline Themes & Similarities \\
\hline $\begin{array}{l}\text { Importance of } \\
\text { physical } \\
\text { meetings (site } \\
\text { visits) }\end{array}$ & $\begin{array}{l}\text { Sales to new potential customers in all of the three } \\
\text { case firms require physical meetings: The sales } \\
\text { process of Sapotech always starts with a demo } \\
\text { project, that is, an installation at the customer's site, } \\
\text { Luxmet CEO stresses the importance of face-to-face } \\
\text { interaction and direct personal meetings with the } \\
\text { customers and the CEO of SFTec considers } \\
\text { physical meetings and site visit highly important } \\
\text { At later stages of the sales process, face-to-face } \\
\text { meetings can be replaced by virtual tools. All firms } \\
\text { use videos and telecommunication to support } \\
\text { interaction. Hence, as customer relationships } \\
\text { mature, firms can reduce the amount of continuous, } \\
\text { direct interaction in sales }\end{array}$ \\
\hline
\end{tabular}

Differences

The type of offering (product or service) and value add has an impact on the need and role of physical meetings, although all three case firms see site visits necessary. The more "virtual" the offering, the easier it is to present to customers. The Sapotech offering provides visualized data and examples of these visualizations can easily be shared over the internet. Luxmet's offering is the results of data direct interaction in sales

analysis that are always customerspecific, where the customerspecificity brings the challenges. SFTec provides physical products, the benefits of which are hard to demonstrate over the internet

Relationship The three growing microenterprises have based initiation and their relationship initiation plans on a steady customer relationship dynamics in pre and during Sapotech's service business (remote connections COVID-19 times between the firm's and customers' systems) continued and brought some monthly cash flow As traveling and site visit restrictions have been slowly removed, SFTec cases have been reactivated

Virtual meetings All three case firms were using virtual (online) and other technological tools' role in response to COVID-19 pandemic meeting tools already before the COVID-19 pandemic. During the pandemic, the use and variety of the use of these tools increased Regarding the new sales deals, all case firms agree that virtual tools can be used up to a certain point, then there is a need for a personal visit

Customer trust and the lack of physical meetings
All microenterprises found a lack of personalized touch as a barrier for closing sales deals. For the case firms, the COVID-19 has made access to case firns, the COVID-19 has made access to mutual trust is an important factor and this trust is built in face-to-face meetings

Communication tools cannot be used to build similar trust, but they provide the means to get to the same tables with the customers

The fact that no one can travel; that is, everyone is in the same position, including competitors and buyers, is making the use of telecommunication tools a new normal

\section{Customer relationship management}

61 difference between customer relationship development (sales work) and relationship initiation activities (innovation and tailoring to customer needs), although they have different foci: Sapotech looks to scale its activities and Luxmet and SFTec to enter new partnerships and customer relationships Communications technologies can be used for different purposes. SFTec used already existing "low-entry" common tools for end-user interaction (WhatsApp videos). Luxmet used video presentations as a substitute for physical meetings. Sapotech provided customers access to existing systems over the internet as a demonstration

Customers in different countries may have different levels of knowledge and adoption, as well as readiness

d, for the understanding of and acceptance of the use of virtual tools. This may be related to national culture or be specific to the industry Based on the evidence from the three microenterprises, sellers rather than buyers appear to be the leaders or trendsetters in the use of trust creation over virtual tools

Table 2. Similarities and differences in the case firms in terms of relationship initiation and customer relationship management 


\section{IJOA \\ 30,7}

\section{Implications and future research directions}

Beyond its major worldwide health implications, the COVID-19 pandemic has unexpectedly emerged as a major shock to the global economy and businesses. It overturned many business practices (Arslan et al., 2021b) and disrupted B2B relationships between valuecreating industrial partners (Crick and Crick, 2020; Cankurtaran and Beverland, 2020). Amid new realities imposed by the pandemic, many businesses and especially microenterprises took refuge in emergency practices without an elaborate design and predictable implications. In particular, social distancing, compulsory working from home and measures imposed against business travel (Arslan et al., 2021b) meant that the nature of B2B relationship initiation and customer relationship management faced noteworthy alterations. As such, the need emerged for understanding how microenterprises faced B2B relationship management-related challenges posed by the COVID-19 pandemic. Therefore, the purpose of the current paper was to analyze B2B relationship initiation and customer relationship management dynamics in industrial firms in the context of the ongoing COVID-19 pandemic.

Our findings offer both theoretical and managerial implications based on in-depth case studies of three Finnish high-tech industrial microenterprises. A key theoretical implication relates to the need for specific theory development concerning microenterprises, which engage in B2B dealings as well as industrial production. In B2B settings, boundary spanners play an important role in the formation of trust between exchange partners. Boundary spanners connect different organizations and enable the creation of value through the exchange of tacit knowledge. All case firms are microenterprises, which adjusted relatively fast to the COVID-19 pandemic despite some hurdles. This is rather different from large manufacturing firms where established routines, processes and hierarchy takes hold as barriers against change imposed by the COVID-19 pandemic. In contrast, a wide network of established relationships may function as a hedge against the problems stemming from the lack of physical contact and site visits, especially in terms of initiating new relationships and building trust.

On the one hand, a fast adjustment by microenterprises, which can be attributed to them being agile (Ponce et al., 2017), can be beneficial for handling B2B relationships in the aftermath of the COVID-19 pandemic. On the other hand, microenterprises need to constantly finding new customers and building trust through personal relationships, rather than relying on brand equity and established profile/references that large enterprises enjoy, which can pose daunting challenges concerning losing physical connections with prospective and current customers. Thus, our research advances the understanding of the unique $\mathrm{B} 2 \mathrm{~B}$ relationships related to challenges faced by microenterprises in the aftermath of the COVID-19 pandemic as well as distinct means they use to tackle the challenges they face.

Another theoretical implication of the current paper relates to the perception and usefulness of technological tools in the context of B2B relationship development and the role of culture (country context) in it. We found that the perception and usefulness of technological tools vary across the relationship stage and the country background of the (potential and current) B2B partners. In particular, we found that virtual communication facilitated by technological tools could be alternative to physical meetings when relationships are well-established and norms and expectations between partner firms are clear. However, physical meetings emerged as vital for initiating a B2B relationship and building trust between new partners. Developing personal relationships and holding physical meetings were essential for developing familiarity between partners and a more holistic understanding of both parties' technical and relational expectations. Likewise, while case firms' (current and potential) customers located in the emerging markets of Poland, 
India and Turkey, insisted on physical meetings despite being shown online demonstrations of the product as well as virtual discussions. Accordingly, our findings indicate the nuanced usefulness of technological tools as substitutes for the loss of physical connections and personal relationships in $\mathrm{B} 2 \mathrm{~B}$ exchange.

Our research also offers a number of managerial implications. First, our findings reveal that, despite technological advancements and challenges imposed by the COVID-19 pandemic, physical meetings continue to be critical for B2B relationships. In particular, when microenterprises seek to initiate new relationships, build trust and form partnerships with customers from countries where personal connections are vital to the health of the $\mathrm{B} 2 \mathrm{~B}$ partnerships, they are advised to make effective use of personal ties and physical touch and abstain from relying excessively on virtual means of communication. Second, our findings also reveal that physical meetings' importance diminishes as relationships mature and norms and expectations are established. Thus, boundary spanners working in microenterprises can invest greater time and effort into communicating with their B2B partners through online channels once trust is built and partners are familiar with each other. Finally, our findings also highlight the importance of quick adaptations to unexpected and largescale disruptions (in the case of our paper, the COVID-19 pandemic) when managing $\mathrm{B} 2 \mathrm{~B}$ relationships. In particular, we suggest that firms channel their efforts and investments to maintain personal relationships and physical meetings when they are indispensable and move swiftly to online communication channels when possible.

Despite the important contributions of this study, some limitations offer significant opportunities for future research. First, future studies can examine B2B firms across both developed and emerging markets and understanding how these firms mitigate external shocks and create value. Second, firms might have to adjust their business models in response to external shocks. Thus there is a need to examine how B2B and business to consumer firms develop and scale up their business models in response to external crises. Third, boundary spanners play an important role in creating value through the exchange of tacit knowledge. Therefore, future studies need to explore how boundary spanners deal with external and external stakeholders in response to crises. Lastly, cognitive proximity is important to develop social ties and trust with exchange partners. Thus, future studies could examine the moderating role of institutional distance and technological advancement in the formation of social ties and trust between exchange partners.

\section{References}

ALHussan, F.B., Al-Husan, F.B. and Alhesan, L. (2017), "The role of senior executives in managing key customers in Arab context", Journal of Business and Industrial Marketing, Vol. 32 No. 6, pp. 825-835.

Arslan, A., Gölgeci, I. and Larimo, L. (2021b), "Expatriates, rise of telecommuting and implications for international business", in: Marinov, M.A. and Marinova, S.T. (Eds), Covid-19 and International Business: Change of Era, Routhledge, New York, NY.pp. 156-166.

Arslan, A., Golgeci, I., Haapanen, L., Tarba, S., Cooper, C. and Degbey, W.Y. (2020), "Cause-related marketing, legitimacy and internationalization of professional service firms", International Marketing Review, Vol. 37 No. 5, pp. 885-899.

Arslan, A., Golgeci, I., Khan, Z., Al-Tabbaa, O. and Hurmelinna-Laukkanen, P. (2021a), "Adaptive learning in cross-sector collaboration during global emergency: conceptual insights in the context of COVID-19 pandemic", Multinational Business Review, Vol. 29 No. 1, pp. 21-42. 
IJOA

30,7

Autry, C.W. and Golicic, S.L. (2010), "Evaluating buyer-supplier relationship-performance spirals: a longitudinal study", Journal of Operations Management, Vol. 28 No. 2, pp. 87-100.

Baluku, M.M., Kikooma, J.F., Bantu, E. and Otto, K. (2018), "Psychological capital and entrepreneurial outcomes: the moderating role of social competences of owners of micro-enterprises in East Africa", Journal of Global Entrepreneurship Research, Vol. 8 No. 1, pp. $26-49$.

Barmeyer, C., Stein, V. and Eberhardt, J.M. (2020), "Third-country nationals as intercultural boundary spanners in multinational corporations", Multinational Business Review, Vol. 28 No. 4, pp. 521-527.

Bouguerra, A., Gölgeci, İ., Gligor, D.M. and Tatoglu, E. (2019), "How do agile organizations contribute to environmental collaboration? Evidence from MNEs in Turkey", Journal of International Management, Vol. 100711.

Calhoun, M. and Harnowo, A. (2015), "Balancing IJV knowledge contributions and trust needs", The Multinational Business Review, Vol. 23 No. 3, pp. 200-223.

Cankurtaran, P. and Beverland, M.B. (2020), "Using design thinking to respond to crises: B2B lessons from the 2020 COVID-19 pandemic", Industrial Marketing Management, Vol. 88, pp. 255-260.

Chandler, J.D., Danatzis, I., Wernicke, C., Akaka, M.A. and Reynolds, D. (2019), "How does innovation emerge in a service ecosystem?”, Journal of Service Research, Vol. 22 No. 1, pp. 75-89.

Corbin, J. and Strauss, A. (2014), Basics of Qualitative Research: Techniques and Procedures for Developing Grounded Theory, Los Angeles, CA, Sage.

Cortez, R.M. and Johnston, W.J. (2020), "The coronavirus crisis in B2B settings: crisis uniqueness and managerial implications based on social exchange theory", Industrial Marketing Management, Vol. 88, pp. 125-135.

Creswell, J.W. and Miller, D.L. (2000), "Determining validity in qualitative inquiry", Theory into Practice, Vol. 39 No. 3, pp. 124-130.

Crick, J.M. and Crick, D. (2020), "Coopetition and COVID-19: collaborative business-to-business marketing strategies in a pandemic crisis", Industrial Marketing Management, Vol. 88, pp. 206-213.

Crosby, L.A., Evans, K.R. and Cowles, D. (1990), "Relationship quality in services selling: an interpersonal influence perspective", Journal of Marketing, Vol. 54 No. 3, pp. 68-81.

Davies, A. and Hobday, M. (2005), The Business of Projects: managing Innovation in Complex Products and Systems, Cambridge, Cambridge University Press.

Doney, P.M. and Cannon, J.P. (1997), "An examination of the nature of trust in buyer-seller relationships”, Journal of Marketing, Vol. 61 No. 2, pp. 35-51.

Eisenhardt, K.M. (1989), "Building theories from case study research", Academy of Management Review, Vol. 14 No. 4, pp. 532-550.

Fischer, C.S. (1982), "What do We mean by 'friend'? An inductive study”, Social Networks, Vol. 3 No. 4, pp. 287-306.

Gligor, D.M. and Autry, C.W. (2012), "The role of personal relationships in facilitating supply chain communications: a qualitative study", Journal of Supply Chain Management, Vol. 48 No. 1, pp. 24-43.

Gölgeci, I., Murphy, W.H. and Johnston, D.A. (2018), "Power-based behaviors in supply chains and their effects on relational satisfaction: a fresh perspective and directions for research", European Management Journal, Vol. 36 No. 2, pp. 278-287.

Håkansson, H. and Snehota, I. (1989), "No business is an island: the network concept of business strategy", Scandinavian Journal of Management, Vol. 5 No. 3, pp. 187-200.

Hartmann, N.N. and Lussier, B. (2020), "Managing the sales force through the unexpected exogenous COVID-19 crisis”, Industrial Marketing Management, Vol. 88, pp. 101-111. 
Hofacker, C., Golgeci, I., Pillai, K.G. and Gligor, D.M. (2020), "Digital marketing and business-tobusiness relationships: a close look at the interface and a roadmap for the future", European Journal of Marketing, Vol. 54 No. 6, pp. 1161-1179.

Hurley, R.F., Hult, G.T.M. and Knight, G.A. (2005), "Innovativeness and capacity to innovate in a complexity of firm-level relationships: a response to woodside (2004)", Industrial Marketing Management, Vol. 34 No. 3, pp. 281-283.

Jeong, S.W. (2016), "Types of foreign networks and internationalization performance of Korean SMEs", Multinational Business Review, Vol. 24 No. 1, pp. 47-61.

Khan, Z. and Nicholson, J.D. (2014), "An investigation of the cross-border supplier development process: problems and implications in an emerging economy", International Business Review, Vol. 23 No. 6, pp. 1212-1222.

Kogut, B. and Zander, U. (1992), "Knowledge of the firm, combinative capabilities, and the replication of technology", Organization Science, Vol. 3 No. 3, pp. 383-397.

Kotabe, M., Martin, X. and Domoto, H. (2003), "Gaining from vertical partnerships: knowledge transfer, relationship duration, and supplier performance improvement in the US and Japanese automotive industries", Strategic Management Journal, Vol. 24 No. 4, pp. 293-316.

Lehtimäki, T., Salo, J., Hiltula, H. and Lankinen, M. (2009), "Harnessing web 2.0 for business to business marketing-Literature review and an empirical perspective from Finland", Faculty of Economics and Business Administration, Vol. 29, p. 76.

Luo, X., Griffith, D.A., Liu, S.S. and Shi, Y.Z. (2004), "The effects of customer relationships and social Capital on firm performance: a Chinese business illustration", Journal of International Marketing, Vol. 12 No. 4, pp. 25-45.

Matanda, M.J. and Freeman, S. (2009), "Effect of perceived environmental uncertainty on exporterimporter inter-organisational relationships and export performance improvement", International Business Review, Vol. 18 No. 1, pp. 89-107.

Mohr, J. and Spekman, R. (1994), "Characteristics of partnership success: partnership attributes, communication behavior, and conflict resolution techniques", Strategic Management Journal, Vol. 15 No. 2, pp. 135-152.

Mullins, R.R. and Panagopoulos, N.G. (2019), "Understanding the theory and practice of team selling: an introduction to the special section and recommendations on advancing sales team research", Industrial Marketing Management, Vol. 77, pp. 1-3.

Murphy, M. and Sashi, C.M. (2018), "Communication, interactivity, and satisfaction in B2B relationships", Industrial Marketing Management, Vol. 68, pp. 1-12.

Nätti, S., Pekkarinen, S., Hartikka, A. and Holappa, T. (2014), "The intermediator role in value cocreation within a triadic business service relationship", Industrial Marketing Management, Vol. 43 No. 6, pp. $977-984$.

Padmavathy, C., Balaji, M.S. and Sivakumar, V.J. (2012), "Measuring effectiveness of customer relationship management in Indian retail banks", International Journal of Bank Marketing, Vol. 30 No. 4, pp. 246-266.

Patton, M.Q. (2002), "Two decades of developments in qualitative inquiry: a personal, experiential perspective", Qualitative Social Work, Vol. 1 No. 3, pp. 261-283.

Plessis, M.D. and Boon, J.A. (2004), "Knowledge management in eBusiness and customer relationship management: South African case study findings", International Journal of Information Management, Vol. 24 No. 1, pp. 73-86.

Ponce, D.K.P., Lorenzo, A.F. and Concepción, R.R.F. (2017), "Innovation management: the need of a model for manufacturing micro-enterprises", Quality Innovation Prosperity, Vol. 21 No. 3, pp. 1-14.

Price, L.L. and Arnould, E.J. (1999), "Commercial friendships: service provider-client relationships in context”, Journal of Marketing, Vol. 63 No. 4, pp. 38-56. 
IJOA

30,7

66

Schilke, O. and Cook, K.S. (2013), "A cross-level process theory of trust development in interorganizational relationships", Strategic Organization, Vol. 11 No. 3, pp. 281-303.

Takala, J., Hirvelä, J., Liu, Y. and Malindžák, D. (2007), "Global manufacturing strategies require “dynamic engineers?”, Industrial Management and Data Systems, Vol. 107 No. 3, pp. 326-344.

Varoutsa, E. and Scapens, R.W. (2018), "Trust and control in evolving inter-organisational relationships: evidence from the aerospace industry", Accounting, Auditing and Accountability Journal, Vol. 31 No. 1, pp. 112-140.

Walker, D. and Rowlinson, S. (2007), Procurement Systems: A Cross-Industry Project Management Perspective, Oxon, Routledge.

Williams, P. (2002), “The competent boundary spanner", Public Administration, Vol. 80 No. 1, pp. 103-124.

Williams, T.A., Gruber, D.A., Sutcliffe, K.M., Shepherd, D.A. and Zhao, E.Y. (2017), "Organizational response to adversity: fusing crisis management and resilience research streams", Academy of Management Annals, Vol. 11 No. 2, pp. 733-769.

Yin, R.K. (2009), Case Study Research: Design and Methods, 4th ed., London, Sage.

Corresponding author

Ahmad Arslan can be contacted at: ahmad.arslan@oulu.fi

For instructions on how to order reprints of this article, please visit our website: www.emeraldgrouppublishing.com/licensing/reprints.htm

Or contact us for further details: permissions@emeraldinsight.com 